\title{
Policy System Design of National Energy Transformation
}

\author{
Xiao Xinli*1,a ${ }^{\text {Xu Zhicheng }}{ }^{1, \mathrm{~b}}$ \\ ${ }^{1}$ State Grid Energy Research Institute Co.,Ltd. Binhe Street 18\#, Future city North, Beiqijia Town, Changping District, Beijing, China
}

\begin{abstract}
The Transition of clean and renewable energy to fossil energy as well as the clean use of fossil energy is the main trend of energy system, which promotes energy system transform to a clean efficient and intelligent status. Accordingly, related policies transform to efficiency and benefit, technical innovation, based on energy security. This paper bases on scientific analysis of the evolution trend of energy transformation and energy policy system, designs energy transformation policy system in the aspect of implementation aims and objects, in order to provide references for energy system transformation.
\end{abstract}

\section{Background}

Traditional fossil energy contributes basic and decisive power to the process of world economic development, while the processes of fossil energy production, transportation and consumption cause pollution and ecological destruction, which not only become the world's important obstacles for the sustainable development of economic, social, environmental governance process, but also have brought the huge economic loss. Meanwhile, the total amount of fuel energy gradually becomes key constraints for national political, social and economic development. Thus, basing on the fields of total volume optimization, technological innovation, market reform, exploring new and renewable energy to replace the traditional fossil energy has become the focus of energy transformation.

Policies play a guiding and restricting role in the development process from traditional energy to new diversified energy sources. For example, the introductions of policies and standards for electric vehicles and charging piles play an important role in the development of electric vehicle industry; and subsidy policies for wind power and photovoltaic are also key external forces for the industrial development. In order to effectively and accurately transform to clean, efficient and energy saving, energy transformation must be carried out in a systematic and indepth analysis of various energy categories and links, so as to identify the development weaknesses of each process and promote the rapid development of the industry through the formulation of corresponding policies.

\section{Analysis of current situation and trend of energy transformation policy development}

In promoting energy transformation, countries always focus on the factors of internal and external political situation, resource endowment, technological level, environmental constraints. The energy transformation process cannot be separated from the support and requirements of national policies. Meanwhile, the continuous development of the energy transformation process will also have an impact on the policy system. Through the analysis of the current situation and development trend of the national energy transformation and corresponding policies, a theoretical and practical foundation is laid for the design of the policy system of energy transformation.

\subsection{Energy transformation trend analysis}

National energy transformation is a process of centering on the needs of political, economic and social development, and gradually replacing dominant energy sources and then accordingly adjusting the whole energy system. Among them, the substitution effect of the dominant energy is mainly reflected in the gradual increase of the total amount of new energy consumption and the subversive adjustment of the energy structure. Furthermore, it has a key impact on the economic and social development of the country and the region, including the changes in the infrastructure, technology, talents and other aspects of energy production, transportation and consumption, as well as the changes in government organizations and the structure of market subjects.

With the constant fluctuations of the global political pattern, economic situation and environmental constraints, national energy transformation has gradually given more consideration to environmental protection, technology and other factors on the basis of ensuring stable supply of basic energy and reasonable consumption. Therefore, new characteristics of the energy transformation shows like intellectualization, information, depuration, low carbon.

(1) Security and stability are the basic prerequisites for energy transformation. Security is the bottom line and basic premise of energy transformation. Only when

\footnotetext{
${ }^{*}$ axiaoxinli@sgeri.sgcc.com.cn bxuzhicheng@sgeri.sgcc.com.cn
} 
political, economic, social and other aspects are in a safe and stable state can we ensure the orderly propulsion of all processes of energy transformation. Therefore, the energy transformation should not endanger security, such as the impact of the rapid layout of new energy on the safety of the power system, the impact of accelerating de-coal on the security of energy supply, and the impact of the rapid transformation of electrified coal to electricity on people's livelihood.

(2) Overall coordination is the basic requirement of energy transformation. In the formerly development of economy, society, the energy just acts as a material foundation. With the deeply coupled trend of international political pattern and the development of domestic economic, social, environmental trend, energy acts the same strategic role as political, economic, social and environmental elements, of which energy and other factors have mutual influences and significant synergies between each other. Thus, energy transformation process reflects the trends of overall planning, collaborative promotion.

(3) Efficiency is the ultimate issue in the energy transformation. The limited resources and short-term nonrecovery of traditional fossil energy, directly determine that each process of energy production, transportation, consumption should remain efficient, and then reduce the burden of energy consumption costs on the economy. Although wind energy, photovoltaic energy, tidal energy and other renewable features are gradually replacing fossil energy, the investment required in energy development and utilization has also become a barrier to large-scale replacement of fossil energy with renewable energy. Efficiency is therefore a key consideration for both fossil and renewable energy sources.

(4) Technological innovation is a key driver of energy transformation. Energy and electric technologies accelerate iterative innovation and significantly improve the efficiency and benefits of all energy industries, fields and processes. At the same time, technologies such as 'big data, cloud computing, Internet of Things, mobile internet as well as block chain' accelerate the penetration in the energy field and promote the iterative innovation in the energy field. In the current high-speed information age, technology rapidly iterates, which promotes the emergence of new forms of business and new models in the energy field, and promotes the energy transformation and upgrading to high quality and high efficiency.

(5) Marketization is the fundamental approach to energy transformation. The traditional mode of planned energy management brings about a series of problems, such as low efficiency of resource allocation and low enthusiasm of market subjects. Gradually opening up the competitive process and restoring the commodity attribute of energy are the necessary links in the reform of state administrative system and economic system, as well as the internal demand for promoting the efficient allocation of resources in the field of energy.

\subsection{A review of policy evolution trends}

The policy system is an important guarantee for achieving the goal of energy transformation[1]. A sound and reasonable policy system will ensure the overall coordination of the interests of all parties and the smooth flow of various elements in the energy sector, thus forming a soft support for energy transformation.

(1) Strengthening market reform is the basic orientation. The market-oriented reform in the energy sector is always in progress. Although the traditional planned policy controls the energy price, the main body and other details in the planned economy period, which has produced great benefits, the planned energy management system is gradually transforming and upgrading towards the marketization with the progress of China's economic reform. The government gradually releases power to the market and reduces administrative intervention in the detailed operation of the market. In order to realize more efficient allocation of resources in the energy field, the opening borders of competitive fields and natural monopoly processes are gradually clarified, and various entities such as private capital and foreign capital are gradually opened up to participate in the energy market, so as to promote the role of the invisible hand of the market.

(2) Regional policies constitute an important supplement to the energy policy system. In response to the state's call for decentralization of energy regulation, the state and local energy administrations have gradually delegated some of their power to lower levels so that they can perform their respective functions and operate efficiently. The state energy administration is responsible for the formulation of policies such as energy strategic planning, pricing, laws and regulations, and the development of environmental protection and clean energy. While local energy administrative departments, in close combination with local characteristics, formulate policies and regulations on the overall development of regional energy, so as to ensure the healthy and orderly development of regional energy.

(3) A systematic energy policy system urgently needs to be formed. China's reform and development process has been in the progress of constant exploring, which has no ready experience to learn from. Therefore, the energy policy system shows obvious problem orientation, which easily leads to mutual restriction or contradiction in the development of relevant policies in various energy categories and processes. In order to ensure the integrity and systematicness of the energy policy system, the factors like energy security, economic development, environmental improvement should be ensured first, and transform from short-term interest to long-term interest, from problem oriented to multiple target oriented. Energy should not only be paid close attention to, but coordinated development among economic, social factors should also be focused on, so as to build a systematic energy policy system.

(4) Technological innovation becomes a key component of the energy policy system. In light of the obvious trend of in-depth integration of information technology and energy technology, investment in research and development of innovative technologies should be increased, in order to promote rapid deployment of technological innovation in the energy sector, and promote technological innovation of energy enterprises by the form 
of policy funds and price subsidies. To be specific, the capital advantages of energy state-owned enterprises should be made full use of to tackle key problems and basic technologies, laying a foundation for the development of the energy sector. As for some technologies with fast iteration speed, private enterprises and joint ventures can be introduced to carry out technology research and development with low cost and high efficiency through market means, so as to improve the overall technology research and development efficiency in the energy field.

(5) Evaluation of policy implementation results is an essential component of the energy policy system. Policy planning is in the leading position, which is the leader of all activities. In contrast, evaluation of the effectiveness of policy implementation is often neglected. Therefore, it is necessary to establish a scientific and reasonable quantitative evaluation method to evaluate both the subject of policy implementation and the object of policy implementation, so as to form objective and comprehensive evaluation results[2].

\section{Design of energy transformation policy system}

\subsection{Basic path of policy system design}

According to the characteristics of energy system development, the policy support system for energy transformation is designed from the two dimensions of policy implementation purpose and implementation object.

(1) The implementation purpose dimension subdivides policies from the perspective of the original intention of policy formulation. From the dimension of implementation purpose, the policy system contains: 1)guiding policy, namely industry guidance, planning, standard and normative policies; 2) restrictive policies, namely laws and regulations, environmental constraints, and fossil energy utilization indicators, which are mainly used as constraints and red lines for the development of the energy industry; 3) incentive policies, namely through subsidies, fiscal and taxation, investment liberalization and other forms, expand the intensity and scope of participation of energy subjects, in order to promote the rapid development of the industry.

(2) The implementation object dimension distinguishes policies from the object perspective. From the implementation object dimension, the policy system contains: 1) the supply-side policies, mean to realize the full utilization of energy resources and the scale effect of energy development by coordinating the main body, total amount and mode of energy supply; 2) demand-side policies, namely adjusting the total amount, structure and mode of energy use with incentives or constraints on the demand-side, so as to improve the overall efficiency and reduce the cost of energy use.

\subsection{Basic content of policy system design}

Due to the dynamic update of internal and external environment and technological level of energy development, the energy policy system is required to keep dynamic characteristics[3]. According to the basic path of energy policy system design and the current hot topics of energy transformation, the energy transformation policy system matrix is designed[4].

Table1. Policy system matrix

\begin{tabular}{|c|c|c|}
\hline \multirow{2}{*}{ category } & \multicolumn{2}{|l|}{ Table Column Head } \\
\hline & supply-side policy & demand-side policies \\
\hline $\begin{array}{l}\text { guiding } \\
\text { policy }\end{array}$ & $\begin{array}{l}\text { clean energy industry } \\
\text { support policies; } \\
\text { guidelines on energy } \\
\text { planning; } \\
\text { guaranteed acquisition; } \\
\text { electric car; } \\
\text { energy storage; }\end{array}$ & $\begin{array}{l}\text { special planning for electric } \\
\text { vehicles; } \\
\text { energy conservation and new } \\
\text { energy development plan; } \\
\text { guidance for industrial } \\
\text { restructuring; } \\
\text { quotas; } \\
\text { technology standard for energy } \\
\text { storage; } \\
\text { charging facilities construction } \\
\text { standard }\end{array}$ \\
\hline $\begin{array}{l}\text { restrictive } \\
\text { policyy }\end{array}$ & $\begin{array}{l}\text { installed capacity of } \\
\text { thermal power units; } \\
\text { discharge standards and } \\
\text { charges; }\end{array}$ & $\begin{array}{l}\text { total energy consumption; } \\
\text { total pollutant discharge }\end{array}$ \\
\hline $\begin{array}{l}\text { incentive } \\
\text { polic }\end{array}$ & $\begin{array}{l}\text { differential electricity } \\
\text { prices for renewable } \\
\text { energy; } \\
\text { investment preferences } \\
\text { (financial subsidies, import } \\
\text { duties, loans and interest } \\
\text { preferences); } \\
\text { operating subsidies (fuel } \\
\text { preference, enterprise tax } \\
\text { reduction or exemption); } \\
\text { technology research and } \\
\text { development investment } \\
\text { and subsidies; } \\
\text { investment and subsidies } \\
\text { for technology research } \\
\text { and development }\end{array}$ & $\begin{array}{l}\text { operating subsidies for the } \\
\text { construction of charging } \\
\text { facilities; } \\
\text { tax breaks; } \\
\text { green finance }\end{array}$ \\
\hline
\end{tabular}

\section{Conclusions}

China's energy transformation will continue to be safetybased, efficiency-oriented, coordinated and technological innovation, and the corresponding energy transformation policies will be transformed and upgraded to marketoriented, systematic, macro-regional directions. Therefore, this paper designs the policy system of energy transformation from the two dimensions of policy implementation objectives and objects, to promote the orderly and rapid development of key areas and processes from the perspectives of guidance, support and constraints, and then promote the rapid deployment of energy transformation process.

\section{Acknowledgment}

This work was supported by the Science and Technology Project of State Grid Corporation of China: Research on Key Technology and Application for Evaluation and Deduction of New Generation energy development strategy (1300-201957272A-0-0-00).

\section{References}

1. Lu Wengang, Liu Hongyan. Strategies on perfection of energy policy in China[J]. Economic Review 
Journal, 2013(2).

2. Zhu Chao, Shi Zhibin. Study of Environmental Performance Assessment of Key Energy Transformation Policies[J]. Environmental Impact Assessment, 2017, 039(004):P.4-9.

3. ZHAO Dai-qing, CAI Guo-tian, LIAO Cui-ping, WANG Wen-jun, HUANG Ying. Policy Introduction on Energy Transformation and Low Carbon Development Strategy in China Cities[J]. ADVANCES IN NEW AND RENEWABLE ENERGY, 2019, 7(02):88-96.

4. Huang Pu, Sun Zaifu. Analysis on tax policy to promote energy transformation in the perspective of the shift in driving forces for development[J]. Research of Finance and Accounting, 2019, 000(003):5-11. 